\section{Polarized Crystal Spectrum of Potassium Tetrachloroplatinite(II) at Liquid Helium Temperature}

\section{O. SONNICH MORTENSEN}

Department for Physical Chemistry, Chemical Laboratory IV, The University of Copenhagen, Copenhagen, Denmark

A s part of an investigation of the electronic structure of square planar platinum(II) complexes, the polarized crystal spectrum of $\mathrm{K}_{2} \mathrm{PtCl}_{4}$ has been taken at the temperature of liquid helium. The spectrum obtained is shown in Fig. 1 and the oscillator strengths for the separate bands as obtained by Gaussian analysis are shown in Table 1.

Crystal spectra of $\mathbf{K}_{2} \mathrm{PtCl}_{4}$ taken at room temperature have been reported by Yamada, ${ }^{1}$ by Martin and Lenhardt, ${ }^{2}$ and by Day et $a l .^{3}$ The room temperature spectrum obtained here as a preparatory step in the recording of the $5^{\circ} \mathrm{K}$ spectrum was very similar to that reported by Day et $a l .^{3}$ and diverged slightly from that reported by Martin and Lenhardt. ${ }^{2}$

The essential differences between the spectra previously reported and the spectrum reported here, are the following (ignoring the natural decrease in intensity as expected from the vibronic model ${ }^{4}$ ).

(i) The appearance of a band located at $24000(x y)$ and $23940(z) \mathrm{cm}^{-1}$ (ii) The appearance of structure in the bands at $20700(z), 23940(z)$ and $26000 \mathrm{~cm}^{-1}$.

The progression reaching from 23000 to $28000 \mathrm{~cm}^{-1}$ contains some 19 members separated by $270-290 \mathrm{~cm}^{-1}$, the progression around $23940(z) \mathrm{cm}^{-1} 8$ members separated by $275-295 \mathrm{~cm}^{-1}$, and the progression around $20700 \mathrm{~cm}^{-1}(z), 3 \mathrm{mem}$ bers separated by $260-280 \mathrm{~cm}^{-1}$.

The totally symmetric ground state vibrational frequency $\alpha_{1 g}$ is known ${ }^{5}$ to be $335 \mathrm{~cm}^{-1}$, so on account of the widely extended progressions we must identify
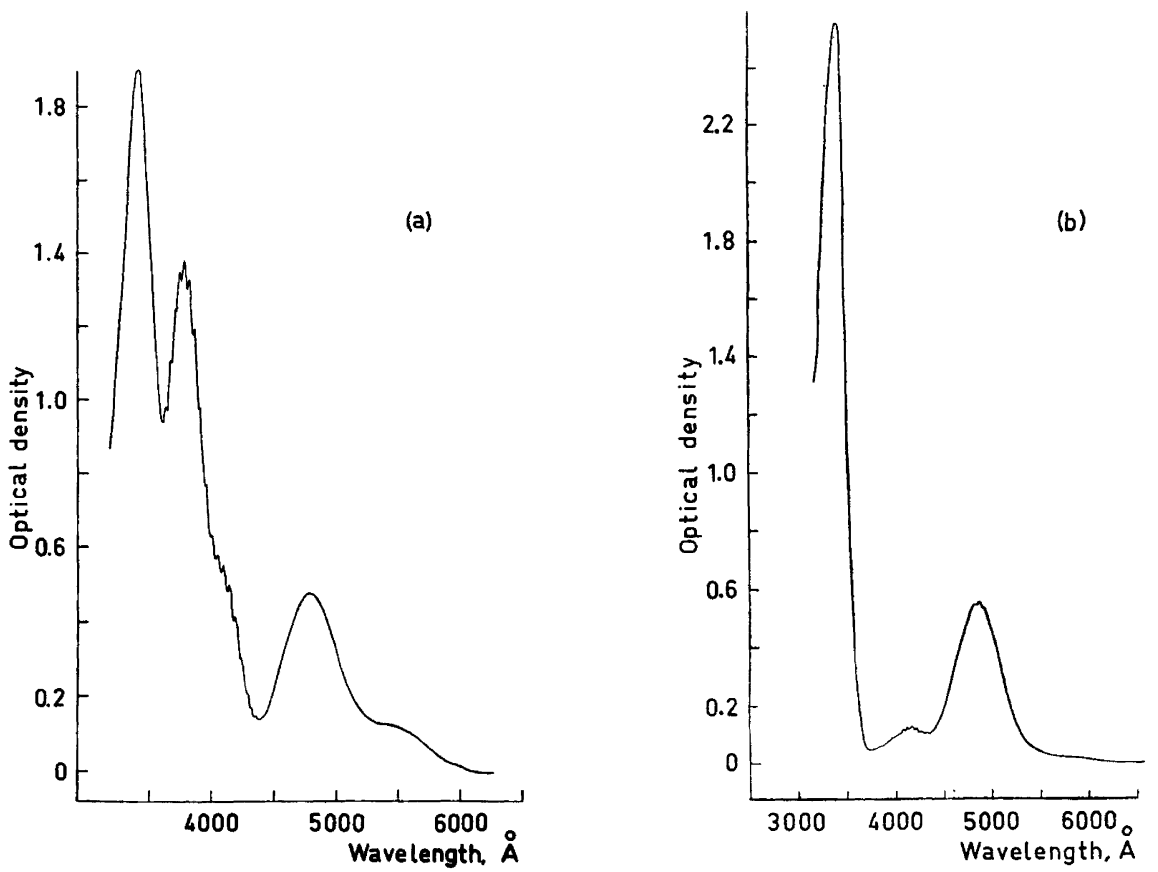

Fig. 1. $5^{\circ} \mathrm{K}$ crystal spectrum of $\mathrm{K}_{2} \mathrm{PtCl}_{4}$ polarized $x y$ (a) and $z$ (b). The $z$ axis is coincident with the fourfold axis.

Acta Chem. Scand. 19 (1965) No. 6 
Table 1. Band maxima and oscillatorstrengths in $5^{\circ} \mathrm{K}$ spectrum of $\mathrm{K}_{2} \mathrm{PtCl}_{4}$.

\begin{tabular}{ccl}
\hline$\nu_{\max } \mathrm{cm}^{-1}$ & $\begin{array}{c}\text { oscillator- } \\
\text { strength } \times 10^{4}\end{array}$ & polarization \\
\hline 17190 & 0.03 & $z$ \\
16930 & 0.005 & $x y$ \\
18100 & 0.09 & $x y$ \\
20660 & 0.77 & $z$ \\
20810 & 0.73 & $x y$ \\
23940 & 0.13 & $z$ \\
24000 & 0.35 & $x y$ \\
26050 & 1.6 & $x y$ \\
29900 & 4.3 & $z$ \\
29250 & 3.6 & $x y$
\end{tabular}

the structure in all the bands as being the normally expected ${ }^{4}$ totally symmetric progression.

The solution and crystal spectrum of the compound has been assigned by a number of authors ${ }^{6-8,2,3}$ however, no one so far has succeeded in a conclusive identification of the band at $20000 \mathrm{~cm}^{-1}$ and the band at $29000 \mathrm{~cm}^{-1}$. A short discussion of an assignment, which seems to be consistent with the now available experimental data is given in the following.

In most previous work the band at $26000 \mathrm{~cm}^{-1}$ has been identified with the ${ }^{1} A_{1 g}-{ }^{1} A_{2 g}$ transition. The $5^{\circ} \mathrm{K}$ spectrum strongly supports this regarding polarization, intensity and structure. The band around $18000 \mathrm{~cm}^{-1}$ seen only $x y$ has been assigned to the ${ }^{1} A_{1 g}-{ }^{3} A_{2 g}$ transition previously because of the polarization which is consistent with the symmetry group $D_{a h}$. However, since the singlettriplet transition is actually seen, the relevant symmetry group is not the single group $D_{4 h}$ but the double group $D_{4} h^{\prime}$. In this group ${ }^{3} A_{2 g}$ is split into the components $\Gamma_{1}$ and $\Gamma_{5}$, neither of these by reason of symmetry being polarized only $x y$. The ${ }^{3} E_{g}$, however, has a $\Gamma_{2}$ component which should be polarized only $x y$, and this could be identified with the band at $18000 \mathrm{~cm}^{-1}$.

The statement by Chatt et al. ${ }^{6}$ that neither the band at $29000 \mathrm{~cm}^{-1}$ nor the band at $20000 \mathrm{~cm}^{-1}$ is split under lower symmetry suggests that the $29000 \mathrm{~cm}^{-1}$ band is ${ }^{1} B_{1 g}$ and the $20000 \mathrm{~cm}^{-1}$ band the $\Gamma_{3}$ component of ${ }^{3} E_{g}$. The ${ }^{1} A_{1 g}-{ }^{1} E_{g}$ transition then should be located at a somewhat higher energy and could be identified with the shoulder at $36500 \mathrm{~cm}^{-1}$ reported by Day et $a l .^{3}$ in the reflectance spectrum and the shoulder at $37900 \mathrm{~cm}^{-1}$ reported by Chatt et $a l .^{6}$ in the solution spectrum. This shoulder is not seen in the solution spectrum of related complexes of lower symmetry probably because it is hidden under the very intense charge transfer band located at $46000 \mathrm{~cm}^{-1}$ in the solution spectra of these compounds. The ${ }^{3} B_{1 g}$ is split under the double group into the components $\Gamma_{4}$ and $\Gamma_{5}$ of which $I_{4}^{\prime}$ is expected to have almost zero intensity since no $\Gamma_{4}$ component of the singlet states exists.

The $\Gamma_{5}$ component is able to interact with the $\Gamma_{5}$ components of ${ }^{3} A_{2 g}$ and ${ }^{3} E_{g}$, giving rise to three bands all borrowing intensity from the ${ }^{1} A_{1 g}-{ }^{1} E_{g}$ transition. It is stated by Day et al. ${ }^{3}$ that this transition is polarized more strongly $x y$ than $z$, which is consistent with our spectrum if the band at $24000 \mathrm{~cm}^{-1}$ is identified with the $\Gamma_{5}$ component at higher energy. The two other $\Gamma_{5}$ states are then assumed to contribute to the bands at $18000 \mathrm{~cm}^{-1}$ and $20000 \mathrm{~cm}^{-1}$, consistent both with the fact that these bands show a somewhat greater intensity than expected from the coupled singlet states, and with the blurring out of structure in the $20000 \mathrm{~cm}^{-1}$ (xy) band. The very weak band at $17000 \mathrm{~cm}^{-1}$ is then assigned the $\Gamma_{1}$ components of ${ }^{3} A_{2 g}$ and ${ }^{3} E_{g}$.

The present model seems to account for most of the experimental data and agrees with the molecular orbital scheme described by Gray and Ballhausen. ${ }^{8}$

Two things still seem rather mysterious, the great difference between the $x y$ and $z$ maxima in the band at $29000 \mathrm{~cm}^{-1}$, and the complete absence of any structure in this band. The difference cannot be explained from the difference in frequency of the exciting vibrations, since these all have ground state frequencies of the order of $100-300 \mathrm{~cm}^{-1}, 5,9,10$ but it might be that a deeper insight into the nature of the vibronic model and especially its influence on the potential surface could provide an explanation.

It must be said again that the assignment given here is strongly tentative. A conclusive identification should, however, be possible on the basis of a low temperature crystal spectrum of a related compound as $\mathrm{Pt}\left(\mathrm{NH}_{3}\right)_{2} \mathrm{Cl}_{2}$. Attempts in this direction are in progress. 
Acknowledgment. The author wants to thank Professor C. J. Ballhausen for excellent working facilities at the Laboratory for Physical Chemistry, H. C. Ørsted Institute, and Dr. Raymond Dingle for his interest and help in this work.

1. Yamada, S. J. Am. Chem. Soc. 73 (1951) 1182.

2. Martin, D. S. and Lenhardt, C. A. Inorg. Chem. 3 (1964) 1368.

3. Day, P., Orchard, H. F., Thompson, H. J. and Williams, R. J. P. J. Chem. Phys. 42 (1965) 1973.

4. Ballhausen, C. J. Introduction to Ligand Field Theory, McGraw-Hill Book Company, New York 1962.

5. Stammreich, H. and Forneris, R. Spectrochim. Acta 16 (1960) 363.

6. Chatt, J., Gamlen, G. A. and Orgel, L. E. J. Chem. Soc. 1958486.

7. Fenske, R. F., Martin, D. S. and Ruedenberg, K. Inorg. Chem. 1 (1962) 441.

8. Gray, H. B. and Ballhausen, C. J. J. Am. Chem. Soc. 85 (1963) 260.

9. Adams, D. M. and Gebbie, H. A. Spectrochim. Acta 19 (1963) 925.

10. Sabatini, A., Sacconi, L. and Schettino, V. Inorg. Chem. 3 (1964) 1775.

Received July 5, 1965.

\section{The Reactions of Lignin during Sulphate Cooking}

\section{IX.* Interaction between Thiol \\ Groups and Intermediary Epoxide Structures}

\section{JOSEF GIERER and NILS-HÅKAN WALLIN}

Swedish Forest Products Research Institute, Stockholm Ö, Sweden

D uring sulphate cooking sulfhydryl groups are introduced into lignin. Of the possible pathways of introduction, the addition of sulphide ions present in the cooking liquor to methylene quinone structures formed during the cooking procedure

\footnotetext{
* Part VIII, see Ref. 1
}

appears to be the most important one. ${ }^{1}$ The resulting benzylthiol groups were shown in model studies to enhance the alkaline splitting of neighbouring $(=\beta)$ arylether bonds by intramolecular nucleophilic displacement with formation of 1,2-episulphide structures. ${ }^{2}$

In the present communication we wish to report on model experiments illustrating another type of reaction in which thiol groups may be involved during sulphate cooking.

The alkaline splitting of $\beta$-hydroxyalkylarylether bonds (I) was previously shown to proceed via 1,2-epoxide structures (II). , $^{2,3}$ It could be anticipated that these structures will be attacked by the strongly nucleophilic thiol groups to yield $\boldsymbol{\beta}$-hydroxyalkylsulphides (III). When the

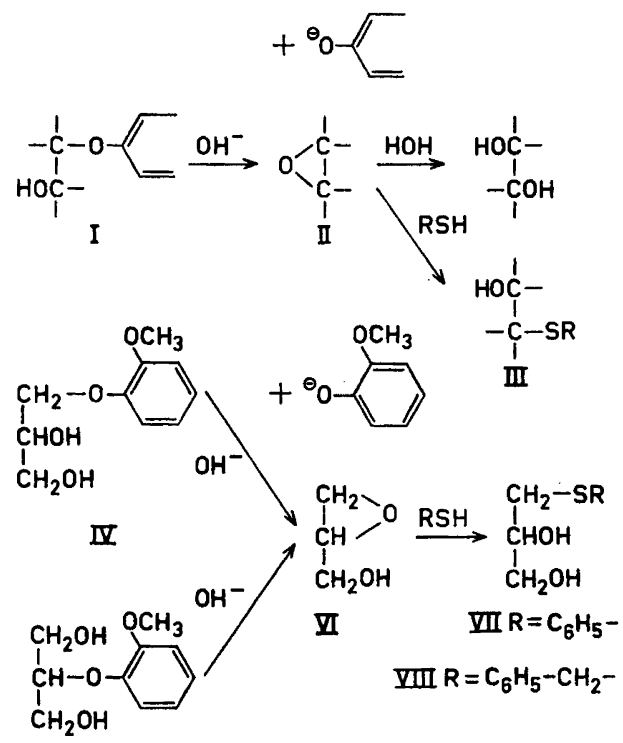

I<smiles>COc1ccc(COc2ccccc2OC)cc1OC</smiles>

$\mathbf{X}$<smiles>COc1ccc(CCSCc2ccccc2)cc1OC</smiles>

$\mathbf{X}$ and $\mathbf{X T}$
Acta Chem. Scand. 19 (1965) No. 6 